\title{
Usage of Urdu as the Language of Elitism among the Muslims of the Northern and the Deccan parts of India: A Socio-Cultural Review
}

\author{
Arshi Siddiqui, ${ }^{1}$ Ismail Siddiqui ${ }^{2}$ \\ ${ }^{1}$ PhD, Barkatullah University, Bhopal (M.P), India. \\ ${ }^{2}$ Integrated Masters, Development Studies, IIT Madras, Chennai, (T.N), India
}

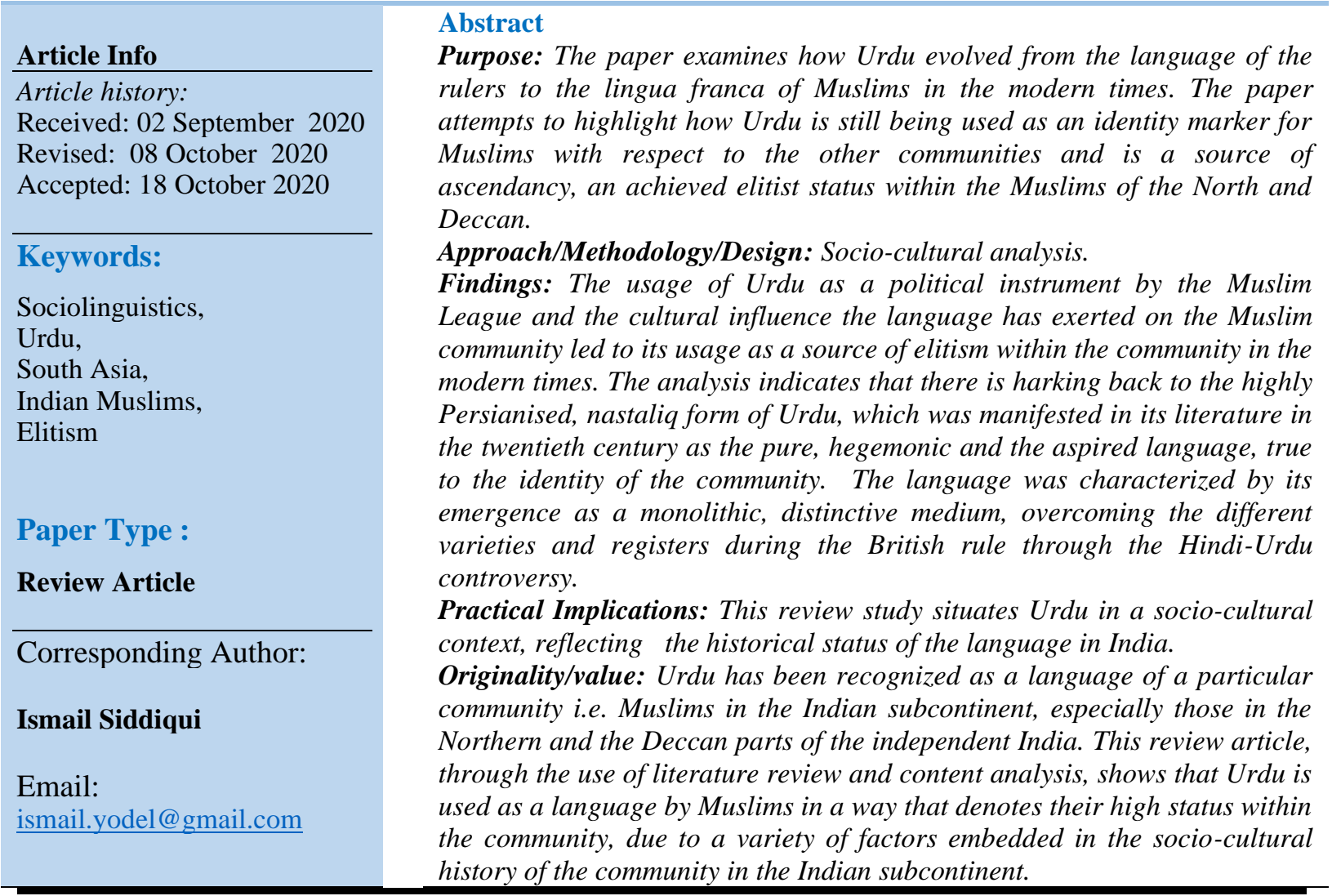

\section{Introduction}

Language is not merely a means of interpersonal communication and influence. It is not merely a carrier of content, whether latent or manifest. It is content, a referent for loyalties and assimilations, an indicator of social statuses and personal relationships, a maker of situations and topics as well as of the societal goals and the large-scale value-laden arenas of interaction that typify every speech community (Fishman, 1970, p. 1).

Urdu hai jiska naam humeen jaante hain 'Daagh'

Saare zamaane mein dhoom humari zuban ki hai 
"Urdu is the name of what we know O Daagh,

The whole world is amazed by our language."

("Dagh Dehlvi - Sher")

This couplet penned by the celebrated $19^{\text {th }}$ century poet Daagh Dehlavi shows the status of the Urdu language among its speakers. A language which is rather a dialect of Hindustani ${ }^{[1]}$ came out to be the identity of the Muslims in India, and South Asia by extension owing to its origins and the political processes. This paper traces how Urdu holds a peculiar position with regards to its status as a language in the subcontinent and its evolution, as well as the identity politics surrounding it, leading to its use by the Muslim community in India in the Northern and the Deccan parts as an identity marker with respect to the other communities and a source of an elitist status within the Muslim society vis-a-vis who don't possess the knowledge of the language. Owing to the literature that started to be produced in the twentieth century, its adoption as the language of Islam in South Asia and the identity politics it was subjected to, Urdu exerts an enormous cultural influence among the Muslims in India which results in the usage of the standard and pure Urdu (of the ashrafs [2], "elites") as a source of elitism within the community.

\section{The Curious Case of Urdu}

Urdu as a language has a very unique case linguistically, historically and sociologically. In the linguistic sense, it can hardly be classified as a totally distinct language from Hindi, or if we go into more technical terms, Hindustani. Urdu nouns and adjectives can have a variety of origins, such as Arabic, Persian, Turkish, Pashto and even Portuguese, but ninety-nine per cent of Urdu verbs have their roots in Sanskrit/Prakrit. Hence, it is an Indo-Aryan language; a branch of Indo-Iranian family, which in turn is a branch of Indo-European family of languages. It can more aptly be called a different register of Hindustani written into a different script, i.e. Persian, filled with Perso-Arabic vocabulary; known as Dakkhani in Southern India. (Afroz, 1997) Being almost fully mutually intelligible with each other, the convergence of Hindi and Urdu was manifested by Hindustani which Mahatma Gandhi wanted to be the national language. Both are understood as a dialect of the Khariboli variant of Hindustani. Though intermingling of various factors has given it a totally unique identity but linguistically, the cases of Farsi (Persian) and Tajik seem to be close to the case of Urdu and Hindi ${ }^{[3]}$.

In a historical sense, Urdu's emergence is more important. It was a language which evolved due to the interaction of the Turk and Persian soldiers as well as rulers with the local population. Deriving its name from the Turkish word for camp, it was originally known as Zubaan e Urdu e Mu'alla which means "exalted language of the camp"; referring to the military origins of the tongue. The name itself suggests that it always accorded a higher status among the populace. The rulers with their armies who came to the Indian subcontinent in the medieval era were Persian and Turkish speakers, and their intercourse with the Indians led to the evolution of Urdu. Although Persian remained the language of the court and administration for a long time, it was Urdu in its infantile stage which remained as the tongue 
of communication between the people of the court as well as the general populace who did not know Persian. The local language was what Khusro ${ }^{[4]}$ has called 'Hindawi' and was not yet Persianised (Rahman, 2011a, p.13-25). Thus, it brings to the light the fact that Urdu never became a colloquial language of the people. It was only used by the elite sections of the population and emerged as a literary language among elite settings. It was only later after the Mughals that Urdu gained wide acceptance and became a lingua franca throughout what is called as Hindustan.

In the sociological perspective, Urdu yet again holds a distinct status. Needless to say, the medieval rulers of most of what today is India were Muslims. In a region where the majority of the population did not subscribe to Islam, these rulers, especially the Mughals, adopted various policies that helped them gain acceptance. At the same time, locals who wanted to get close to the court started learning the language and the practices of rulers. That is how a distinct tongue with heavy sprinkling of Perso-Arabic vocabulary started to emerge. The urban centres witnessed conversations in several languages, each being an identity marker of a particular community; Turanis with Turkish, Iranians with Persian, indigenous population with their own dialects of Hindawi etc. (Rahman, 2011a, p.40). Thus, Urdu never originated as an indigenous language of the local people, it came out to be a colloquial tongue as a distinct medium with a perception of Islamic undertones and a dialect of Hindustani. The name Urdu was first used only around 1780 by the poet Ghulam Hamadani Mushafi (Rahman, 2011, p.16). Persian remained as the language of administration and high culture in India, until the British replaced Persian with English as the language of administration in 1839.

\section{Hindi-Urdu Controversy}

Hindi Urdu controversy refers to a series of debates and disagreements among Indian leaders during the British period over the choice of the language for India. It arose in the $19^{\text {th }}$ century over whether Hindi or Urdu, along with the question of scripts: Persian or Devanagari, be chosen as the national language of the country. The controversy comprised "Hindi" and "Urdu" protagonists each advocating the official use of Hindustani with the Devanagari script or with the Nastaliq ${ }^{[5]}$ script, respectively. Hindi movements advocating the growth of and official status for Devanagari were established in Northern India. Babu Shiva Prasad and Madan Mohan Malaviya were notable early proponents of this movement. This, consequently, led to the development of Urdu movements defending Urdu's official status; Syed Ahmed Khan was one of its noted advocates. (Christopher \& King, 1994).

However the crucial aspect was to define the language. Braj was the dialect which was the dominant literary language in the script. There were conscious attempts later to push Hindi as the Devanagari version of the Khariboli dialect. On the other hand, Urdu's dilemma was that only if you put more Perso-Arabic words in your expression, it becomes Urdu otherwise it remains as Hindustani. It was during this period that the tags with the languages started to appear in a glaring manner i.e. Urdu is the language of Muslims while Hindi is the language of Hindus. While harking back to the legacy of Urdu as the literary language of the courts and 
high culture of the rulers viz. Muslims, Hindi was shown to contain the suppressed culture of the ruled viz. Hindus, the remainder of Sanskrit as well as the golden age which is the pride of Hindus. More immediate reason is the conflict between students educated in Hindi or Urdu for the competition of government jobs. It exhibited the process of "othering", defining the other in order to define the self. Assertions of legacy of the languages resulted in the painting of the languages into communal colours. (Jones, 1981, p. 124)

\section{Identity Politics and the League}

The consequence of Hindi-Urdu controversy was the Urdu movement, propounded most notably by Sir Syed Ahmed Khan. The demand for Hindi, led largely by Hindus, was to Sir Syed an erosion of the centuries-old Muslim cultural domination of India. He claimed that "Urdu was the language of gentry and of people of high social standing, whereas Hindi was to be the vulgar." The success of the Hindi movement led Sir Syed to further advocate Urdu as the symbol of Muslim heritage and as the language of the Muslim intellectual and political class. His educational and political work grew increasingly centred on and exclusively for Muslim interests (Abbasi, 1981, p. 90).

Sir Syed's call for the adoption of Urdu as the language of Indian Muslims won extensive support among the upper aristocratic class of the Muslims. This led to the establishment of organisations such as the Urdu Defence Association and the Anjuman Taraqqi-i-Urdu, committed to the perpetuation of Urdu. This political campaign had its basis in the communal opposition and can be seen as an attempt to re-establish Muslim hegemony, leading to a wedge between Hindus and Muslims which often spilled into a communal conflict.

All India Muslim League took up the issue and began projecting Urdu as essential for the political and cultural survival of Islamic society in India. Muslim politicians like Muhammad Ali Jinnah, Sir Muhammad Iqbal and Liaquat Ali Khan emphasised Urdu as the symbol of Muslim heritage and political identity (Upadhyay, 2003). The political cause of Urdu became a core issue at the heart of the Two-Nation Theory, which advocated that Muslims and Hindus were irreconcilably separate nations ${ }^{[5]}$. Advocates of the Pakistan movement sought to make Urdu a key argument in drawing distinctions with India's Hindu-majority population.

\section{Emergence of Urdu as the Identity}

The Muslims of the Northern, Western and the Deccan (Hyderabad State) started considering Urdu as an inseparable part of their identity. There were serious attempts across the Muslim groups ${ }^{[6]}$ to adopt the language to portray their political identity and mark their divergence from the Nagari and Nastaliq scripts. Usage of script generally signified the user's faith: Muslims generally use the latter script, while Hindus use the former. Urdu tended to be the language of the urban population among the community which also was the support base of the League (Ambedkar, 1945, pp. 16).

Within the ambit of the Urdu movement, linguistic purism was also at work. In order to distinguish itself from Hindi, which was becoming a Sanskritised Khariboli; concerted 
attempts were made to purge it of Sanskrit and indigenous-origin words and fill it with Persian and Arabic vocabulary. The residual prestige of the Islamic heritage languages was high even when Urdu itself was less in demand and remained high till the beginning of the twentieth century. It carried the legacy of Persian- and by extension, Arabic- languages of sophistication, urbanization and gentrification for centuries. Thus, Urdu started to become a language distant from a rural, uneducated and poor individual. It came to be the language of high culture, with complicated and ornate vocabulary; denoting the identity and prestige of the ashraaf, the elite sections of the Muslims (Rahman, 2011 (b), pp. 11).

\section{New Literature}

The twentieth century saw the rise of modern literature in Urdu. Since the language was established as an identity marker of Muslims, the reformist movements among Muslims began influencing the literature to reform the community which was increasingly perceived as decadent. More importantly, these movements emerged due to the existence of strong communal tensions and the rise of Hindu nationalism. Translation of western canonical texts to instil the modern values was felt as imperative. Victorian values were aspired as opposed to the frank sexual references in the medieval texts. The modern texts, on the other hand, endorsed middle class virtues: order, good management, frugality, sobriety, hard work and sexual modesty - just the very things Muslim reformers wanted to reform in their decadent society (Rahman, 2011 (b), pp. 25). This simultaneously came out to be an opportunity to make the language uniform. The regional varieties of the Urdu, viz. Rekhta (the dialect used around Delhi), Awadhi (used around Lucknow) Dakkhani (used in Hyderabad and the Deccan) etc. were being subsumed under a common, monolithic and standard Urdu. This can be exemplified by the writings of 'Allama' Muhammad Iqbal; a poet, philosopher and a Muslim leader, whose training in Persian, heavy influence from Islamic history and his academic life in Cambridge, lent a superlative style to his works. His dense philosophical poetry is heavily infused with ornate vocabulary; at times he inserts Persian lines in his Urdu poetry, which is scarcely comprehensible for a layman with an elementary knowledge of Urdu. Iqbal wanted nothing short of Islamic renaissance, as it was visible in the language he used; a romantic vision of the society which overcomes all differences speaking a high-class tongue which is representative of the identity of the community. Many poets followed suit, and after the Partition of India, there still remains awe for the writings which are identical to the style of Iqbal: embellished with Perso-Arabic vocabulary, obfuscated and lyrical.

\section{A Religious Tongue}

Unlike Arabic, but like Persian, there was nothing intrinsically holy about Urdu. It was part of the Islamic culture and Muslim identity in India because it was the language of the dominant elite. When this elite group lost its political power in the wake of British colonialism, it consolidated its cultural power through the techniques and artefacts of modernity (Rahman, 2006, p. 4). The high number of translations and exegeses of the Quran available in it, its association with teaching in the Madrasas; the Urdu elegies commemorating the martyrdom of Husain which is central to the Shia faith; and the Urdu writings of revivalists and Islamic 
pressure groups such as Ahl-e-hadis, Deoband and Barelvism for dissemination of ideas as well as the debates between the Ulema led Urdu being identified as the language of Muslims and Islam in North India and Pakistan, and by extension, in South Asia (Rahman, 2006, p. 5$11)$.

Allegiance to the faith also came out to be manifested by allegiance to Urdu. Thus, Ulemas especially emphasised, and continue to do so, the usage of Urdu by Muslims in North India. Any well-read or religious Muslim is assumed to have a command over Urdu, as it is identified as the language representing the autonomy of the minority in a Hindu-majority country, as well an indicator of Islam.

\section{Status within the Community}

As it is commonly understood that Urdu is a language of Muslims in India, it attempts to portray a monolithic identity to the community. The graph below shows percentage of Urdu speakers and percentage of Muslims in different states:

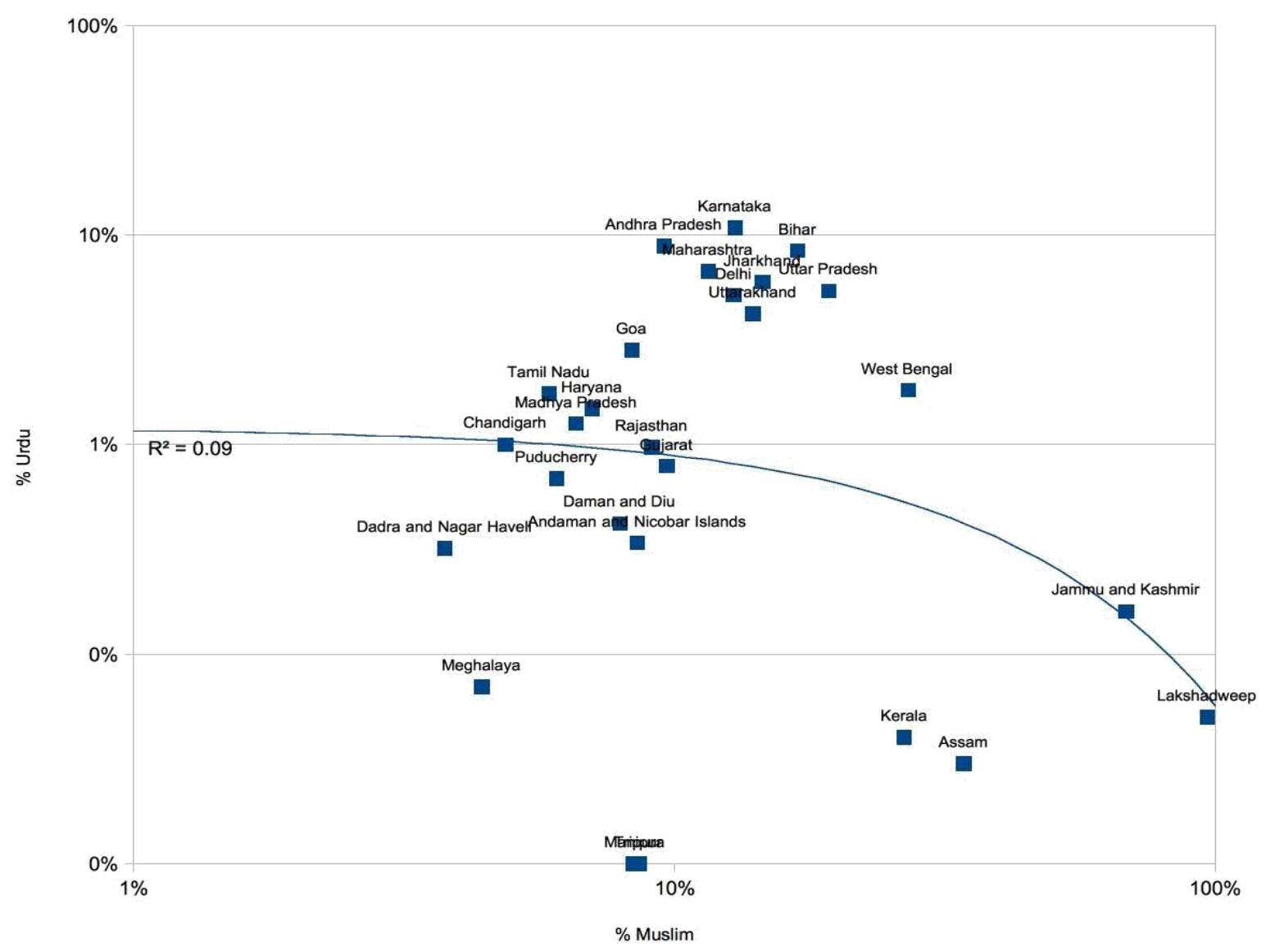

Source: Khan (2018) ${ }^{[7]}$ 
Apart from states like Kerala, Assam and North Eastern states which show almost 0\% of Urdu speakers, there is a fairly corresponding ratio of Urdu speakers and Muslims. In most of the places, especially North and Deccan, Urdu is a second language of Muslims which is representative of the identity rather than the lingua franca, which is the local language in almost all regions. Within the community, Urdu is used as a medium to communicate and disseminate information where those who know the language (especially the script, nastaliq) assume a superior position (normally the ashraaf, "elite") than those who do not (ajlaf, "commoner"). (Rahman, 2006, p. 12) Since people attach subjective significance to their language, the willingness to communicate becomes different from the mere ability to communicate. A uniformity is aspired in the language, which will differentiate the community from the rest and simultaneously grant a superior status to those who know it.

The individuals who grow up in such settings tend to be in a habitus which is classified by the cultural capital that Urdu grants (Bourdieu, 1977). The correct words with the correct pronunciation, knowledge of the nastaliq script and ability to enjoy poetry (shayari) and ghazals is an example of that. Thus, the condescension at those who are unfamiliar with it and cannot appreciate it arises from the cultural capital as a privilege of those who do. A consciousness which is distinct from the Hindu counterparts was, and is, being produced. There is also a process of achieved elite status by learning the language within the community. The Ulema, and to an extent political leadership, use the Persianised Urdu of ashrafs which denotes the prevalent elitism as one invariably cannot achieve such position in the community without the knowledge of the language. The formal register and male sociolect ${ }^{[8]}$ becomes the aspired and the "pure" language. For example, Maulana Ashraf Ali Thanvi, who wrote the Bihishti Zevar ${ }^{\text {[9] }}$, narrates with great disapproval how, upon entering an assembly, women either raise their hand to the forehead in salutation or just say 'salam' (peace). Other respond in the same manner or with traditional blessings: 'may you stay cool' (thandi raho); 'may you live long' (jiti raho); may you live in marital bliss' (suhagan raho) etc. He condemns these indigenous forms of salutation in favour of the strictly Islamic 'As salaam-o-alaikum (peace be upon you) and 'wa-alaikum as-salaam' (peace be upon you too) in response. He also gives a list of words which women pronounce incorrectly and recommends their correct pronunciation in 'standard' Urdu (Thanvi, part 6, p.18).

\section{Conclusion and Suggestion}

The evolution of Urdu exhibits how it has a peculiar status as a language and debates during the colonial era defined its identity. After the creation of Pakistan and Urdu becoming the national language there, it remained in India as a language of the Muslim community and Islamic culture, poetry, and the legacy of the savants as it fell out of administrative usage and mostly from the educational institutions at the elementary level. Thus, largely among the Muslims of Northern and Deccan parts of India, Urdu denotes an identity marker for the community as an attempt to define and differentiate themselves from the rest. On the other hand, within the community there runs a hegemonic discourse which focuses on the usage of pure and standard Urdu, discarding the other sociolects, which is 
highly Persianised and accompanied by the nastaliq script, depicting the glorious legacy of the once-dominant community.

\section{Notes}

[1] Hindustani was the common name of the language spoken in North India; it is seen as the point of convergence between Hindi and Urdu, written in both Persian and Devanagari alphabet.

[2] Ashraf (plural Ashraaf) is an Arabic word which means 'gentleman'. It is used to refer to theelite, urban and so-called upper caste sections of the Muslim society in the Indian subcontinent.

[3] Farsi (Persian) and Tajik are basically the same language, being almost fully mutually intelligible. Their scripts differ, Farsi is written in the Persian alphabet while Tajik adopted Cyrillic (Russian script) due to Soviet influence.

[4] Amir Khusro (1253 - 1325) was a poet and scholar under the Sultans of Delhi. He is credited with developing and writing in what he called Hindawi which was a predecessor of both Hindi and Urdu.

[5] Nastaliq is a variant of the Perso-Arabic script which developed in the $15^{\text {th }}$ century. It is characterised by a tendency to slope downward from right to left, in a fluid style. It was patronised by the Mughals and calligraphers preferred it. The other variant of the PersoArabic script is shikasta.

[6] Urdu came out to be one of the biggest factor, second to only Islam itself, in the assertion of the League that Muslims were different from the majority i.e Hindus and need to protect and preserve their culture in a separate geographical entity.

[7] Examples of Perso-Arabic alphabet being associated with Muslims include the adoption of Arabic alphabets by the Bohras for their variant of Gujarati and by the Muslims of Madras for their sociolect of Tamil called Arwi.

[8] Data taken from the Census of India 2011.

[9] Sociolect refers to the dialect or a variety of speech of a particular social group, class, religion or gender

[10] Bahishti Zevar, "Ornament of Paradise", is a book in Urdu written by Maulana Ashraf AliThanvi (1863-1943). It is a detailed book of prescriptions according to the Sharia and deals with everyday matters of practical life. It is a household name among the Muslims of North India. 


\section{Conflict of Interest}

The authors of the article declare no conflict of interest.

\section{Funding}

This research study was not funded by any institution. The authors conducted the study on their own expenses.

\section{References}

Abbasi, Yusuf. (1981). "Muslim Politics and Leadership in South Asia". Islamabad: Institute of Islamic History, Culture, and Civilization, Islamic University.

Ambedkar, B.R. (1941). Pakistan or Partition of India. Bombay: Thacker.

Bourdieu, Pierre. (1977). Outline of a Theory of Practice. Cambridge University Press.

Fishman, Joshua. (1970). Socio-Linguistics: A Brief Introduction. pp 1-2 Massachusetts: Newbury House Publishers.

Jones, Kenneth. (1981). Religious Identity and the Indian Census in The Census in BritishIndia: New Perspectives. ed. by N.G. Barrier. New Delhi: Manohar.

Khan, Razib. (2018). "Muslims and Urdu in India”. Image. www.brownpundits.com.

Accessed: October 30, 2019. https://www.brownpundits.com/2018/07/04/muslimsand-urdu-in-indial

King, Christopher R. (1994). One language, two scripts. Bombay: Oxford University Press

Rahman, Tariq. (2006). "Urdu as an Islamic Language" .https://www.academia.edu/28526260/Urdu_as_an_Islamic_Language. Accessed: October 20, 2019.

(a). (2011). From Hindi to Urdu: a social and political history. Oxford

University Press, Karachi and Orient Blackswan, Delhi.

(b). (2011). "Urdu as the Language of Education in British India".

Www.academia.edu. Accessed: October 19, 2019.

Taj, Afroz. (1997). "About Hindi-Urdu". The University of North Carolina at Chapel Hill. Thanvi, Ashraf Ali. (2012). Bahishtī Zèvar, Part 6 [The Ornaments of Paradise]. New Delhi: Adam Publishers \& Distributors

R. Upadhyay. (2003) "Urdu Controversy - is dividing the nation further". South Asia Analysis Group. $\quad$ https://web.archive.org/web/20070311170443/http:// www.saag.org/papers7/paper675.html. Accessed 19 September 2020.

"Dagh Dehlvi - Sher". Rekhta, (2020), https://rekhta.org/couplets/urdu-hai-jis-kaa-naamhamiin-jaante-hain-daag-dagh-dehlvi-couplets. 